\title{
Type of Vaccination Facility ICSR Terminology
}

National Cancer Institute

\section{Source}

National Cancer Institute. Type of Vaccination Facility ICSR Terminology. NCI Thesaurus.

Code C114856.

Terminology used in Individual Case Safety Reports to specify the type of vaccination facility. 